\title{
Counterfeit medicines and the unregulated market for drugs
}

\section{Hamid Ghodse}

Editor, International Psychiatry

$T^{\text {he }}$ he unregulated market for medicines has evolved in different ways and exists in different forms in different parts of the world. Given this wide variation, the phrase 'unregulated market for drugs' is commonly used in a generic sense and encompasses the sale of medicines that have been licitly manufactured but diverted from legitimate sales routes as well as the illicit manufacture and sale of (counterfeit) pharmaceuticals. Also within this unregulated environment, prescription-only drugs are sold (illegally) without prescription.

In countries that can offer only limited access to healthcare professionals, hospitals, clinics or pharmacies, unauthorised or unregulated outlets are more likely to exist, because consumers may be forced to buy drugs of whatever sort, from wherever they can. In low- and middle-income countries, the unregulated market may include makeshift outlets at village fairs or on street markets, where medicines are sold along with commodities such as balms, tonics and creams. There are also more organised systems, operated by unscrupulous manufacturers, importers, retailers, wholesalers and healthcare professionals, driven by the possibility of substantial profits. Medicines are likely to be cheaper on the unregulated market.

In higher-income countries, the internet plays a significant role in the unregulated market. It facilitates contact between suppliers and consumers, and offers almost limitless opportunities to sell drugs; delivery to the buyer is often via postal or courier services. The level of privacy offered by internet pharmacies, combined with the weakness of drug regulatory and enforcement mechanisms, contribute to a thriving unregulated market and it is not surprising that the number of illegally operating internet pharmacies continues to rise and has long surpassed the number of licensed and accredited internet pharmacies. They are major suppliers of counterfeit medicines.

Although selling drugs out of a suitcase in a village market may seem very different to selling drugs over the internet, the consequences and the associated problems are similar. Specifically, they offer opportunities for prescription-only medicines to be bought without a prescription, so that powerful drugs become available and may be used in wholly inappropriate ways. In addition, any type of unregulated market represents a useful sales outlet for counterfeit medicines.

\section{The nature of the problem}

Although the existence of counterfeit medicines is not new, their availability was first formally acknowledged as a problem only in the mid-1980s. It has been identified as a growing problem since then, constituting a serious health risk to users. Indeed, the situation has been dramatically worsened by the rapid expansion of unregulated markets, and the World Health Organization (2006) estimates that counterfeits could account for more than $10 \%$ of the global medicines market. The expansion is undoubtedly due to the fact that counterfeiting medicines is a lucrative criminal activity. According to the US Center for Medicines in the Public Interest, counterfeit drug sales will reach US $\$ 75$ billion globally in 2010, an increase of more than 90\% from 2005 (see World Health Organization, 2006).

While counterfeits can be found in all regions of the world, low- and middle-income countries are disproportionately affected. Indeed, according to the World Health Organization (2006), an estimated $25-50 \%$ of the medicines consumed in those countries are counterfeit.

It requires little imagination to appreciate the nature and magnitude of the problem represented by counterfeit medicines, which are specifically manufactured to maximise profits. The products are of doubtful quality, safety and efficacy, and their sources are not guaranteed. In addition to violating intellectual property rights, they undermine healthcare systems through their frequent lack of therapeutic efficacy and safety. Above all, they pose serious health risks to their users because their constituents may be at best ineffective and, at worst, positively harmful (even resulting in death). The problem is compounded by the fact that counterfeit drugs often closely resemble the genuine products in their appearance and packaging. This lulls consumers into believing that they are buying the 'real' drug.

The true criminality of counterfeit medicines is illustrated by the use in Africa of counterfeit vaccines, which, in 1995, resulted in some 2500 deaths (World Health Organization, 2006). It is therefore not an exaggeration to consider trafficking in counterfeit drugs as a potentially life-threatening crime.

\section{Psychotropic medicines}

A wide range of psychotropic medicines, including antidepressants, anxiolytics, stimulants and even narcotic analgesics, are available from unregulated markets in both high-income and low- and middle-income countries. The manufacture and trade of these drugs, which are frequently subject to misuse, are strictly controlled under international conventions and they should be dispensed only on prescription. Their wide availability without prescription via the unregulated market is dangerous for those who may consume them inappropriately and also has public health implications because of the increased risk of misuse and dependence.

Internet pharmacies appear to play a particularly important role in the unregulated market for psychotropic drugs. For example, a recent US survey of 185 internet pharmacies found that $85 \%$ of them sold benzodiazepines, $68 \%$ sold 
opioid analgesics, $8 \%$ sold stimulants and $1 \%$ sold barbiturates; $89 \%$ of them did not require a prescription and only $3 \%$ indicated that, before they dispensed a medicine, a prescription would be required (National Center on Addiction and Substance Abuse, 2006). In 2006, 34 illegal internet pharmacies dispensed more than 98 million dosage units of hydrocodone products (International Narcotics Control Board, 2008). In the USA, the law enforcement authorities examined 1153 imported parcels containing medicinal products during a 3-day operation in 2003. The overwhelming majority of the products (88\%) were illegally imported drugs, including more than 25 different controlled psychotropic medicines, such as diazepam and codeine (Food and Drug Administration, 2003).

\section{Law enforcement and cooperation}

According to a study conducted by the World Health Organization (2003), in 30\% of countries drug regulation is either non-existent or very limited. Clandestine manufacture and trafficking are facilitated by weak drug regulations, weak enforcement of existing regulations and lenient penal sanctions for counterfeiters. If sanctions are not commensurate with the enormous profits that are made, they do not serve as a sufficient deterrent.

Effective action requires the existence of competent national drug regulatory authorities, with a sustained resource base, to ensure control and regular inspection of those involved in the manufacture, trade and distribution of pharmaceuticals.

To regulate the medicines market effectively, national drug regulatory authorities require political will, relevant legislation, appropriate organisational capacity and skilled professionals. The training of healthcare professionals should include guidance on how to promote the rational use of medicines in general and psychotropic medications in particular. Codes of conduct for associations of healthcare professionals, industry and chambers of commerce should address the issue of incorrect or improper handling of drugs. Drug regulatory authorities, law enforcement agencies, manufacturers of pharmaceuticals, professional associations of medical practitioners and pharmacists, as well as consumer protection groups, need to work in concert to identify counterfeit medicines that are in national distribution channels and their sources, so that adequate preventive measures can be undertaken. Without the cooperation of all concerned, there will be little chance to overcome this problem.

These actions at national level need to be complemented by strengthened, concerted international preventive and investigative efforts. National drug regulatory authorities should cooperate effectively in eliminating counterfeit medicines from international commerce. Cooperation and intelligence sharing among national drug regulatory and law enforcement authorities would help to stop shipments of counterfeit medicines and would facilitate the arrest of persons engaged in counterfeiting. Furthermore, national drug regulatory authorities should cooperate with the International Medical Products Anti-Counterfeiting Taskforce, set up with the Declaration of Rome of 18 February 2006. Governments need to be appropriately sensitised to the health and economic risks associated with the counterfeiting of medicines, so that appropriate laws against counterfeiting are enacted, and resources and infrastructure are provided for effective law enforcement at national level.

Apart from governments, the pharmaceutical industry, professional organisations, consumer associations and healthcare professionals, mass media and particularly the health and medical journals all have an important role to play in public education. Psychiatrists, particularly through psychiatric and mental health societies and associations, have a pivotal role to play in relation to the appropriate use of psychotropic medicines, which should include education of both patients and their carers in the risks associated with the use and misuse of medicines, especially those from unregulated sources.

\section{References}

Food and Drug Administration (2003) Customs import blitz exams reveal potentially dangerous import drug shipments. FDA News, 29 September.

International Narcotics Control Board (2008) Report of the International Narcotics Control Board for 2007. United Nations. Available at http:// www.incb.org/incb/en/annual-report-2007.html

National Center on Addiction and Substance Abuse at Columbia University (2006) 'You've Got Drugs!' Prescription Drug Pushers on the Internet: 2006 Update. CASA White Paper.

World Health Organization (2003) Effective Medicines Regulation: Ensuring Safety, Efficacy and Quality. WHO Policy Perspectives on Medicines No. 7. WHO.

World Health Organization (2006) Counterfeit Medicines. Fact Sheet No. 275. WHO. Available at http://www.who.int/mediacentre/factsheets/ fs275/en/

\section{Migration and psychiatric adjustment}

\section{David Skuse}

Behavioural and Brain Sciences Unit, Institute of Child Health, London WC1 1EH, UK, email d.skuse@ich.ucl.ac.uk

$\mathrm{W}$ ith the extraordinarily large movements of populations from some of the former Soviet Union states into Western Europe, since their recent membership of the European Union, attention has been focused in recent years on how easy or otherwise it has been for these people to adjust to life in very different economic and social circumstances. It has been estimated that the UK has absorbed up to a million immigrants from Eastern European states 